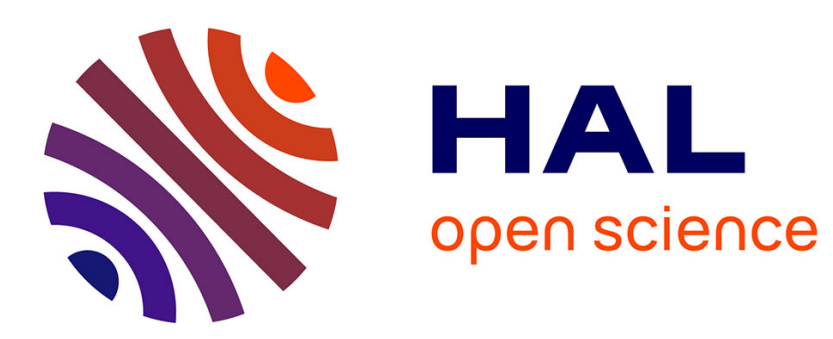

\title{
Zero-sum and frontier trade-offs: an investigation on compromises and compatibilities amongst manufacturing capabilities
}

Roberto Sarmiento, Vinaya Shukla

\section{- To cite this version:}

Roberto Sarmiento, Vinaya Shukla. Zero-sum and frontier trade-offs: an investigation on compromises and compatibilities amongst manufacturing capabilities. International Journal of Production Research, 2010, 49 (7), pp.2001. 10.1080/00207540903555544 . hal-00588660

\section{HAL Id: hal-00588660 https://hal.science/hal-00588660}

Submitted on 26 Apr 2011

HAL is a multi-disciplinary open access archive for the deposit and dissemination of scientific research documents, whether they are published or not. The documents may come from teaching and research institutions in France or abroad, or from public or private research centers.
L'archive ouverte pluridisciplinaire HAL, est destinée au dépôt et à la diffusion de documents scientifiques de niveau recherche, publiés ou non, émanant des établissements d'enseignement et de recherche français ou étrangers, des laboratoires publics ou privés. 


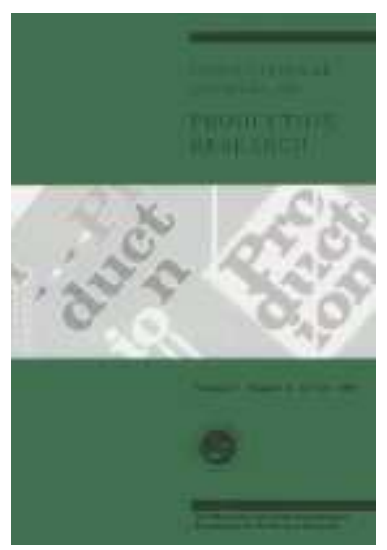

\section{Zero-sum and frontier trade-offs: an investigation on compromises and compatibilities amongst manufacturing capabilities}

\begin{tabular}{|r|l|}
\hline Journal: & International Journal of Production Research \\
\hline Manuscript ID: & TPRS-2009-IJPR-1124 \\
\hline Manuscript Type: & Original Manuscript \\
\hline Date Submitted by the \\
Author: & 06-Dec-2009 \\
\hline Complete List of Authors: & $\begin{array}{l}\text { Sarmiento, Roberto; Cardiff University, Cardiff Business School } \\
\text { Shukla, Vinaya; Cardiff University, BUsiness School }\end{array}$ \\
\hline Keywords: & $\begin{array}{l}\text { MANUFACTURING STRATEGY, REGRESSION ANALYSIS, } \\
\text { BENCHMARKING, HEURISTICS, STATISTICAL METHODS }\end{array}$ \\
\hline Keywords (user): & trade-off model, compatibilities, cumulative capabilities, zero-sum \\
\hline &
\end{tabular}

\section{^scholaroNE \\ Manuscript Central}




\title{
Zero-sum and frontier trade-offs: an investigation on compromises and compatibilities amongst manufacturing capabilities
}

\author{
Roberto Sarmiento* \\ Vinaya Shukla** \\ ${ }^{*}$ Formerly at the Innovative Manufacturing Research Centre \\ Cardiff Business School, Cardiff University \\ Aberconway Building \\ Colum Drive \\ Cardiff, CF10 3EU \\ Wales, UK \\ **Innovative Manufacturing Research Centre \\ Cardiff Business School, Cardiff University \\ Aberconway Building \\ Colum Drive \\ Cardiff, CF10 3EU \\ Wales, UK \\ *corresponding author. Email: sarmientoroberto@yahoo.com.mx \\ ** Tel: 4402920875480 \\ Email: shuklav1@cf.ac.uk
}




\title{
Zero-sum and frontier trade-offs: an investigation on compromises and compatibilities amongst manufacturing capabilities
}

\begin{abstract}
This paper examines well-accepted methodologies and rationales used to assert the presence/absence of trade-offs and compatibilities between manufacturing capabilities, and comparisons are made with respect to more recent theoretical developments. By means of a detailed analysis of a representative framework, important limitations and inconsistencies are identified. The proposal for the existence of zero-sum and frontier trade-offs intends to resolve some of those issues. Generally speaking, zero-sum trade-offs are identified by a statistically significant and negative correlation. On the other hand, frontier trade-offs are predicted to be observed after some level of compatibility between different capabilities is achieved. This means that, apart from widely-used probabilistic methodologies such as linear regression/correlation analysis, subsequent deterministic approaches and rationales need to be applied in order to acknowledge the potential existence of frontier tradeoffs. These and other implications are discussed in light of previous studies, and suggestions for future research are offered.
\end{abstract}

Keywords: trade-off model, compatibilities, cumulative capabilities, zero-sum trade-offs, frontier trade-offs, theory of performance frontiers, probabilistic analyses, deterministic analyses, top performers/extreme cases, thought experiments. 


\section{Introduction}

The importance that trade-offs amongst an organisation's objectives have on its strategy (and hence its competitiveness) has been commented on and discussed by prominent authors in both the business (e.g.; Porter, 1980, 1985; Mintzberg et al, 2003) and manufacturing (e.g.; Skinner, 1969, 1974; Hayes and Wheelwright, 1984; Hill, 1995) strategy fields. The operations management authors in particular have commented that a successful strategy is one that is built around strategic manufacturing trade-offs. Structural (e.g.; production capacity and technology, facilities) and infrastructural (e.g.; quality management systems, human resources management, information technology systems) resources have to be deployed and developed accordingly. Moreover, it is argued that the failure to recognise the existence of these trade-offs could result in a loss of competitive power at the industry/marketplace level (Hayes and Wheelwright, 1984).

A salient theme from this line of research is the approaches and rationales by which researchers, especially in manufacturing strategy studies, have examined and come to the conclusion that different capabilities (e.g.; quality, delivery, cost) are traded-off or compatible. This is a particularly important issue in investigations that employ quantitative approaches to the analysis of the information (e.g.; linear regression/correlation analysis).

In this paper, we intend to address some of the limitations that past empirical and theoretical research on trade-offs and compatibilities between manufacturing capabilities has left pending. By means of a detailed analysis of well-accepted methodologies and assumptions, we arrive at the conclusion that, in order to resolve those issues, two types of compromised relationships between different capabilities need to be recognised: "zero-sum" and "frontier" trade-offs. Zero-sum trade-offs are commonly represented by a statistically significant and negative relationship between two capabilities. Generally speaking, this kind of trade-off is one in which a gain in performance in one capability entails a loss in performance in another capability in a more direct/linear manner. On the other hand, the frontier type of trade-off is characterised by a differential in performance between two capabilities after some level of compatibility is achieved, something that is consistent with the concepts and ideas advanced by various authors (e.g.; Skinner, 1992, 1996; Schmenner and Swink,1998). It is noted that frontier trade-offs are difficult (if not impossible) to identify with probabilistic and overall associative approaches to the analysis of a 
sample of subjects (e.g.; linear regression/correlation analysis, path analysis). Thus, it is proposed that additional and more focused and deterministic (i.e.; precise) analyses, including those with a heuristic "benchmark" approach also be employed. It can also be said that zero-sum trade-offs represent a relationship between two capabilities that can be far more "adversarial" than when two capabilities are in a frontier trade-off. As such, the differential in performance caused by a zero-sum compromise is expected to be considerably greater than the one caused by a frontier trade-off.

We discuss the findings of our investigation in light of past theoretical and empirical research. For example, we argue that when some studies have claimed to offer evidence against the existence of trade-offs between different capabilities in their samples, they are really offering evidence only against the existence of zerosum trade-offs, but not against the potential existence of frontier trade-offs. Zerosum compromises might be contingent upon various circumstances and conditions (e.g.; Safizadeh et al, 2000; Flynn and Flynn, 2004). Also, when authors have acknowledged and/or provided evidence that some trade-offs can be improved but not eliminated (e.g.; New, 1992; Skinner, 1992, 1996; da Silveira and Slack, 2001), they have arguably made an implicit reference to a frontier trade-off that governs the relationships between different criteria. The potential presence of frontier trade-offs implies a change in the way compromises and compatibilities amongst manufacturing capabilities are understood. This means that, as opposed to what current rationales propose, compatibilities (e.g.; cumulative capabilities) and (frontier) trade-offs can coexist within the same sample of subjects. To the best of our knowledge, this is the first investigation that examines the issues outlined above. The consequences of these and other results are discussed, and proposals for future research are offered.

The rest of the paper is organised as follows: section 2 deals with the definitions and background of our investigation. Specific research questions are laid out. Section 3 presents an analysis on well-accepted approaches and rationales, and compares them with more recent theoretical developments. Inconsistencies and limitations are highlighted, and the existence of zero-sum and frontier trade-offs is advanced in order to resolve some of those issues. Section 4 compares the findings of our investigation with those of previous research, and section 5 offers conclusions and suggestions for future studies. 


\title{
2 Trade-offs and compatibilities amongst manufacturing capabilities: definitions and background
}

\begin{abstract}
2.1 Definitions
In order to achieve clarity, several concepts and definitions need to be established. Therefore, a trade-off situation is defined as one in which a firm achieves high levels of performance in one manufacturing capability at the expense of lower levels of performance in one or more capabilities (i.e.; a gap in performance that represents a differential in competitive power). This definition is consistent with the trade-off model's original tenets: “.... no technologically-based system can perform equally well on every performance criterion ....." (Skinner, 1996, p. 8). In this context, a "high" level of performance is defined as an "... outstanding enough .... to create competitive advantage" (Skinner, 1996, p. 6) level of achievement in one or more capabilities. The preceding statements imply that, at the very least, different capabilities that are traded-off will not attain an "outstanding enough to create competitive advantage" type of performance at the same time and under the same circumstances. This definition includes the meaning of the "frontier" and "zero-sum" trade-offs introduced in section 1.
\end{abstract}

A compatibility situation implies that there is evidence of an overall and similar degree of performance achievement up to a determined level between different capabilities. This definition of "compatibility" covers the characterisation of "cumulative capabilities" that has been used by previous authors (e.g.; Ferdows and de Meyer, 1990; Noble, 1995; Flynn and Flynn, 2004). Nonetheless, contrary to the definition of "cumulative capabilities", "compatibility" does not necessarily imply, for example, that just because different capabilities observe a generally compatible situation (e.g.; a positive and significant correlation/regression coefficient), such a scenario indicates that the analysed criteria have achieved, or will eventually achieve, an "outstanding enough to create competitive advantage" level of performance at the same time and under the same circumstances. Put differently, our definition of compatibility allows for the presence of both "cumulative capabilities" (e.g.; mutual progression) and (frontier) trade-offs (i.e.; a differential in performance with respect to higher levels of achievement) in a relationship between different capabilities. 
We also advance a heuristic and deterministic (i.e.; precise) approach to analyse compromises and compatibilities between competitive criteria. The firms are first identified according to the levels of performance they achieve across the different capabilities included in the analysis. Then, for each individual firm, we make assessments of performance between different pairs of manufacturing capabilities in terms of the mutual levels of achievements and also the shortfalls/differentials in performance with respect to higher levels of achievement. This, in turn, will allow us to focus on the "top performers" (i.e.; a benchmark approach) in order to understand more fully the trade-offs and/or compatibilities that might exist between different pairs of capabilities. The "top performer (s)" is defined as the firm (s) that observes the highest levels of achievement across multiple capabilities in a sample. This would mean that, for instance, the ideal top performer (s) would be the firm (s) that achieves an outstanding enough to create competitive advantage type of performance across all manufacturing capabilities at the same time. Section 3 explains this approach in more detail.

Schmenner and Swink (1998, p. 108) affirm that an asset frontier is defined by and dependent upon the kinds of investments that appear on the fixed asset portion of the balance sheet. Furthermore, they assert that, as firms approach their asset frontier, trade-offs between different capabilities will become more evident. These relationships are characterised by the laws of diminishing returns and synergy ${ }^{1}$. Figure 1 illustrates these concepts:

\section{Take in figure 1}

\section{$2.2 \quad$ Theoretical background}

There has been much interest in examining whether manufacturing firms can become industrial/marketplace leaders across several or all manufacturing

\footnotetext{
1 The law of diminishing returns entails a proportional (e.g.; linear) relationship between two variables that becomes a disproportional (e.g.; nonlinear) one after a certain point in the relationship is reached. Thus, when Schmenner and Swink (1998) state that their framework rests on this premise, it can be derived plausibly that the "cumulative capabilities" they speak of in their framework are represented by the proportional aspect of the relationship, whereas "trade-offs" are exemplified by the non-proportional aspect of it (see for example the discussion in page 110 of Schmenner and Swink, 1998).
} 
capabilities. The underlying idea, evidently, is to achieve excellence in performance that in turn will provide firms with a competitive advantage. Let us consider Skinner's actual words: "one system cannot be outstanding enough at meeting all criteria to create competitive advantage" (Skinner, 1996, p. 6). Also: “... no technologicallybased system can perform equally well on every performance criterion" (Skinner, 1996, p. 8). Putting those two statements together, the conclusion is that the trade-off model actually predicts that no manufacturing system can perform equally well and outstandingly enough across every performance criterion at the same time. Therefore, it is recommended that companies should adopt a "focused factory" approach to the design, development, and implementation of the strategy and operations of a production unit. Echoing Skinner's arguments, Hayes and Wheelwright (1984, p. 41) also warn against trying to compete by offering superior performance in all manufacturing capabilities, since any attempt to do so would likely result in firms achieving only a second-best type of performance in all of them, something that in turn would make them lose competitiveness. It follows from the preceding discussion that in order to conclusively assert that no trade-off is present in a relationship between any pair of capabilities, a firm or firms would have to attain an "outstanding enough to create competitive advantage" type of performance across those capabilities at the marketplace/industrial level of analysis and under the same circumstances.

On the other hand, various authors have proposed what they consider to be competing, more complete and comprehensive models and theories. For example, the cumulative capabilities models (e.g.; Ferdows and de Meyer, 1990) and rigidflexibility models (e.g.; Collins et al, 1998) offer alternative views on the development of strong capabilities. The basic idea behind these models is that some (or all) tradeoffs can be overcome, particularly if continuous improvement programs such as TQM, JIT, TPM, etc., are successfully implemented. It is also worth noting that it is not clear whether the proponents of the cumulative capabilities and rigid-flexibility models affirm that all trade-offs can be overcome or simply that a production unit can be "outstanding enough to create competitive advantage" on more than one or two capabilities. A literature review identifies a number of studies that deal with diverse aspects of the trade-off model and/or its competing concepts, with varying results and conclusions (Ferdows and de Meyer, 1990; Roth and Miller, 1990, 1992; Noble, 1995; Schroeder et al, 1996; Mapes et al, 1997; Morita and Flynn, 1997; Szwejczewski et al, 1997; Fillipini et al, 1998; Collins et al, 1998; Flynn et al, 1999; Fynes at al, 2000; Mapes et al, 2000; Safizadeh et al, 2000; Dostaler, 2000, 2001; da 
Silveira and Slack, 2001; Corbett and Whybark, 2001; Corbett and Claridge, 2002; Stratton and Warburton, 2003; Lapre and Scudder, 2004; Rosenzweig and Roth, 2004; Flynn and Flynn, 2004; Narasimhan et al, 2005; Fynes et al, 2005; da Silveira, 2005; da Silveira, 2006; Grobler and Grubner, 2006; Squire et al, 2006; Swink et al, 2006; Stratton and Warburton, 2006; Sarmiento et al, 2007; Antonio et al, 2007; Sarmiento et al, 2009).

An analysis of the aforementioned studies shows some evidence that firms are capable of achieving synergies, mutual progression, and in some cases, what could be considered as high levels of performance on a number of capabilities. Nonetheless, it can also be concluded that the main tenets of the trade-off model have not been refuted. In other words, the reviewed investigations do not offer evidence supporting the existence of a firm or firms that have actually achieved an "outstanding enough to create competitive advantage" level of performance across all manufacturing capabilities.

A key topic in this area of research concerns the way in which authors have determined that two or more capabilities are traded-off or compatible. The reviewed studies show a favoured approach to the examination of these themes: researchers obtain from firms cross-sectional data (perceptual and/or objective) representing manufacturing performance metrics (e.g.; cost, delivery). The data is then analysed using quantitative and probabilistic approaches (e.g.; linear regression/correlation analysis and related methodologies). Generally, analysts have come to the conclusion that different capabilities are in a trade-off or in a compatibility (e.g.; "cumulative capability") situation if they observe significant negative or positive correlation coefficients, respectively. For example, Safizadeh et al (2000, p. 117) write: “.. a positive correlation means parallel developments of two capabilities. A negative correlation implies trading-off one capability for another". Such definitions imply that, since the trade-off model and its seemingly competing theories have been depicted as mutually exclusive concepts, previous authors have chosen to assert the presence of two competing concepts (e.g.; trade-offs or cumulative capabilities) based on mutually exclusive types of evidence (i.e.; significant negative or positive correlations) that describe overall associations amongst variables within a sample of subjects. The type of compromised relationship described in those studies is consistent with the zero-sum trade-off introduced in section 1. 
As previously mentioned, the above methodologies and rationales have been widely accepted and used in past research. Nevertheless, we think that more recent theoretical developments have important repercussions on those approaches. For example, various authors in the operations and strategic management areas (e.g.; New, 1992; Skinner, 1992, 1996; Schmenner and Swink, 1998; Porter, 1996) have suggested that while there may be instances in which different criteria can observe mutual improvements and parallel trajectories along their development, strategic trade-offs and compromises are still existent, relevant, and should not be overlooked. Thus, if compatibilities and compromises can be observed along the development of two capabilities, it follows that approaches capable of identifying both trade-offs and compatibilities in a relationship are necessary. Such approaches should be consistent when the unit of analysis is a group of firms or individual firms. These premises suggest a reassessment and re-evaluation of current methodologies and rationales used in these types of studies in order to determine whether they are consistent with newer theoretical developments. Consequently, when contradictions or inconsistencies are found, they need to be resolved.

The re-evaluation of well-accepted methodologies and rationales raises a number of important questions. For example, are regression/correlation analyses capable of identifying the potential trade-offs and compatibilities that can exist between a pair of competitive criteria as implied by more recent theoretical investigations? If not, what types of approaches are needed? If new approaches are needed, how can they be reconciled and made consistent with past methods and rationales? The rest of the paper will attempt to answer these questions.

\section{An investigation on trade-offs and compatibilities}

Consistent with Schmenner and Swink (1998), we utilise "thought experiments" to illustrate and support our arguments. The use of thought experiments is a well-accepted approach in areas such as physics (Popper, 2002). Nevertheless, some researchers (e.g.; Folger and Turillo, 1999) have also discussed the usefulness of such an approach in business management studies. Therefore, our use of this type of experiment is justified. By means of a detailed analysis of a framework that is representative of more recent theoretical developments, we explore the potential advantages and limitations of widely accepted methodologies and rationales. To resolve some of the issues that past investigations did not identify and 
thus left unresolved, we formally acknowledge the existence of zero-sum and frontier trade-offs.

\subsection{Rationale for the existence of frontier trade-offs}

To support our arguments for the existence of frontier trade-offs, we use the illustration advanced by Schmenner and Swink (1998, figure 1 in this paper). However, one addition is made in order to highlight some issues within that framework. Figure 2 shows this:

\section{Take in figure 2}

We have added a positive regression/correlation line to Schmenner and Swink's (1998) original framework to represent the "cumulative capabilities" they say are present in their illustration. As was discussed in section 2, a positive and significant linear regression/correlation coefficient is a widely used and well-accepted means to depict "cumulative capabilities". Furthermore, figure 2 suggests a positive and significant trajectory, as the firms included in it are portrayed to move upwards and to the right along the development of their capabilities. Therefore, we think that our inclusion of the regression/correlation line in figure 1 is valid. Having said this, we also identify a particular issue: Schmenner and Swink (1998) argue for the existence of both "cumulative capabilities" and "trade-offs" in their framework. They also comment that such compromises are observed after cumulative capabilities are attained, and that those trade-offs become more evident the closer a firm gets to its asset frontier. Thus, it can be said within reason that the trade-off implied by the theory of performance frontiers cannot be one that is consistent with an overall linear and negative regression/correlation analysis. As was discussed in section 2 , such a coefficient is also a well-accepted means to assert the presence of a compromised relationship. To sum up, figure 2 implies a scenario in which both compatibilities and a trade-off that is not representative of a negative and significant regression/correlation line have to be fitted into one single framework.

To understand better and to attempt to resolve the above issues, we propose to extend the framework presented in figures 1 and 2 to include several firms at 
Figure $3^{3}$ illustrates the "cumulative capabilities" and (frontier) "trade-off" predicted by the theory of performance frontiers in an ideal form. It also includes different ways in which the sample of firms can be analysed.

\section{Take in figure 3}

The preceding figure represents the proportional and disproportional aspects of a relationship between two variables as suggested by Schmenner and Swink's (1998) framework. Therefore, if a researcher were to investigate the relationship between MC1 and MC2 by means of current rationales and approaches, he/she would very likely conclude that "cumulative capabilities" exist between the two variables in the study, and that there is no evidence of any trade-offs. This would be based on the positive and significant regression/correlation line and coefficient obtained. Nevertheless, it is clear that such a conclusion would be incomplete. While

\footnotetext{
${ }^{2}$ Although using perceptual measures of performance is consistent with the trade-off model's aims and goals, it could also be possible to utilise objective measures of achievement (e.g.; " $98 \%$ on-time delivery rates, " $30 \%$ of defective product"), as long as the sample includes firms from the same industry and similar context, or comparable competitors so that reasonable comparisons with respect to the marketplace-leading performers can be made.

${ }^{3}$ Figure 3 can also be understood as an ideal "picture" of a single firm as it advances in the development of two capabilities that observe both "cumulative capabilities" and (frontier) "trade-offs", as implied by several authors.
} 
it is true that the positive and significant regression/correlation line would be an acceptable and overall indicator of the "cumulative capabilities" that exist in the framework (e.g.; a 1/1 ratio between MC2 and MC1 as shown by firms A, B, C and D), this method would not be able to identify the existing differential in performance between MC1 and MC2 (i.e.; a frontier trade-off) as observed in firm "E" (e.g.; a 4/5 ratio between MC2 and MC1). Such a compromise would be the result of the presence of the asset frontier as proposed by Schmenner and Swink (1998), which in turn would mean that only one capability would attain a level 5 in performance, while the other one would achieve only a lesser level of performance (e.g.; level "4"). This differential in achievement clearly would be in accord with the definition of trade-offs advanced by Skinner (1992, 1996). The problem, nevertheless, resides in the fact that an overall methodology such as linear regression/correlation analysis would "mask" or "hide" the (frontier) trade-off caused by the asset frontier and that is expected to take place at the higher levels of performance. Arguably, methodologies based on the central tendency behaviour of the observations, such as linear regression/correlation analysis and related methodologies, would be incapable of detecting and distinguishing the differential in performance that is predicted to occur at the highest levels of the performance continuum and the closer a firm gets to its asset frontier.

Given these limitations, we think that a more correct and holistic analysis of the sample, as well as of individual observations, needs to include but also go beyond regression/correlation analysis. We propose a deterministic and heuristic approach to analyse each individual firm. Assessments with respect to both commonalities in performance achievements (e.g.; cumulative capabilities) and also shortfalls and differentials in performance (e.g.; trade-offs) amongst the criteria in discussion can be made. For example, let us re-examine figure 3 , assuming that the researcher is not aware of the presence of a (frontier) trade-off. By analysing the firms individually, it could be said within reason that there is evidence of mutual progression and compatibilities in achievement between MC1 and MC2 up to the "4" level of performance, and that this trend is supported by an overall positive and significant regression/correlation coefficient. Nonetheless, by means of a deterministic "benchmark" analysis of the sample that focuses on the top performers (firms "D" and "E"), it can also be affirmed that the similar level of mutual progression, achievements, and compatibilities was not replicated at the level " 5 " of performance (i.e.; there is a differential in performance between MC1 and MC2, as seen in firm E), which in turn could be indicative of the presence of a (frontier) trade-off between MC1 
and MC2. Arguably, focusing on the "best performers" (e.g.; firms that achieve "high levels of performance" in one or more capabilities) gives the researcher the best chance at analysing whether such high levels of performance could have come at the expense of lower levels of achievement in one or more different capabilities. Ideally, more focused and corroborative case studies (including longitudinal ones) would also be performed.

We think that our proposed heuristic approach and rationale to the analysis of the results is more complete than the way in which previous authors have examined the evidence and derived their conclusions in studies using a quantitative approach with cross-sectional data. For instance, various studies claim to present no results that support the existence of trade-offs in their samples ${ }^{4}$ (e.g.; Ferdows and de Meyer, 1990; Noble, 1995; Flynn and Flynn, 2004). However, such a rationale is limited, because, while the lack of a significant and negative relationship might indicate the absence of a (zero-sum) trade-off, it is possible that a frontier trade-off could still be present, as our analyses have shown. To sum up, achievements in performance should be interpreted both in terms of the mutual levels of progression and compatibilities that the criteria under study observe, and also in terms of the performance shortfalls identified with respect to higher levels of achievement, which in turn could be indicative of the presence of a frontier trade-off.

We now proceed to justify the existence of zero-sum trade-offs.

\subsection{Rationale for the existence of zero-sum trade-offs}

It could be said that trade-offs of the zero-sum type, while not identified and labelled as such, is the most widely accepted form in which a compromised relationship between variables has been portrayed and understood. Our analyses of the trade-off model literature reveal that such an assumption is commonly used by previous investigations when assessing whether trade-offs between two different criteria exist, particularly in quantitative studies (e.g.; Ferdows and de Meyer, 1990; Safizadeh et al, 2000; Flynn and Flynn, 2004). Generally, a significant and negative regression/correlation coefficient has been taken as an indication of this type of

\footnotetext{
${ }^{4}$ One way in which past studies assert the absence of a negative and significant relationship (and hence the absence of a (zero-sum) trade-off) is by means of a positive and significant coefficient between two capabilities. Another way is by means of a non-significant coefficient.
} 
trade-off. As footnote 4 explains, the absence of such a coefficient has been explained as the lack of evidence of a compromised relationship between two variables. Figure 4 illustrates an ideal version of this type of trade-off:

\section{Take in figure 4}

As can be seen, the relationship shown above reflects a trade-off situation, a differential in performance between MC3 and MC4 (e.g.; fast delivery and marketbased quality, as in Flynn and Flynn, 2004) observed particularly at the highest levels of performance. This is also consistent with the definition of a compromised relationship as proposed by Skinner $(1992,1996)$. It is also evident that, as opposed to the case in which frontier trade-offs are present, linear regression/correlation analyses would be a fairly adequate tool to identify this latent trade-off.

The previous paragraphs have dealt with various issues that our research into the trade-off model and related concepts has raised. The acknowledgement of the existence of both zero-sum and frontier trade-offs reconciles some of those difficulties. This implies a change and re-evaluation of the rationales used to assert that two variables are in a compatible and/or compromised situation. Moreover, figures 3 and 4 show that the compromises in performance that zero-sum and frontier trade-offs represent are considerably different (e.g.; under a zero-sum trade-off, firm "E" would attain a " 5 " along MC3, but only a "1" in MC4; under a frontier trade-off, firm "E" achieves a "5" along MC1, but only a "4" in MC2). Also, it bears repeating that the presence of the asset frontier implies that both compatibilities (e.g.; cumulative capabilities) and (frontier) trade-offs between two criteria can exist in the same sample of subjects, and that it is important to extend current methodologies and rationales used in these types of studies in order to acknowledge such a situation.

\section{Discussion}

Previous investigations offer some evidence of the several situations described and discussed in section 3. For example, two studies (Safizadeh et al, 2000; Flynn and Flynn, 2004) have shown evidence of zero-sum trade-offs between different capabilities. These trade-offs seem to be contingent upon various situations 
and scenarios (e.g.; production technology). Frontier trade-offs, on the other hand, have not been explicitly identified and discussed as such. Nevertheless, da Silveira and Slack (2001) write that managers view trade-offs differently from academics, and that while some trade-offs can be improved, they cannot be eliminated. Their results arguably could be indicative of the frontier trade-offs that we have identified. The consensus amongst researchers that have studied manufacturing trade-offs seems to be that evidence of a compromised relationship can only be asserted by means of a significant and negative correlation coefficient. Nevertheless, as our investigation has shown, a frontier type of trade-off is also a latent possibility that can explain why different capabilities, while observing mutual progression and compatibilities up to a certain level of performance, will not attain the same compatibility at higher levels of achievement.

We think that frontier trade-offs have a plausible theoretical basis. For example, Skinner $(1992,1996)$ and New (1992) acknowledge the possibility that some trade-offs could be improved, but not eliminated, by the adoption of more advanced manufacturing technologies. Skinner (1992) in particular goes on to explain that two capabilities that are traded-off may run in parallel or counter to each other at different levels or amplitudes, but in the end, one will attain a higher level of performance than the other one. Thus, a pair of variables under the effect of a frontier trade-off could be indicative of Skinner's words: while they might be compatible even at the higher levels of performance, in the end, only one of them will attain an "outstanding enough to create competitive advantage" type of performance. Schmenner and Swink (1998) and their research into the asset frontier also offer strong support for the frontier trade-off concept identified in our investigation.

Another important issue concerns the potential causes of both zero-sum and frontier trade-offs. Various authors (e.g.; Schonberger, 1986, 1990; Ferdows and de Meyer, 1990; Noble, 1995) imply that the absence of high implementation levels of JIT, TQM and related practices might cause a zero-sum trade-off between different criteria. Nevertheless, from the studies that present evidence of such trade-offs (Safizadeh et al, 2000; Flynn and Flynn, 2004), it can not be concluded that the negative and significant relationships observed are due to a lack of implementation of those practices. On the other hand, Safizadeh et al (2000) present an interesting result: zero-sum trade-offs seem to be dependent upon the production technology utilised. For example, "cost" and "delivery" observe a significant and negative relationship in batch shop processes, but no similar situation is reported for other 
types of production technologies. A similar scenario occurs between "quality" and "customisation", which has a zero-sum relationship in continuous flow shops, but no significant relationship in other types of production technologies. With regards to the causes of frontier trade-offs, from Schmenner and Swink (1998), we can derive that these compromises are caused by the asset frontier. Adding to the potential causes of competitive advantage, Vastag (2000), in his comments on the theory of performance frontiers, argues that, excluding some special circumstances, the sources of sustained competitive advantage are more likely to come from infrastructural factors within firms (i.e. operating frontier) than from structural ones (i.e.; asset frontier). Also, Skinner $(1992,1996)$ suggests that structural and/or infrastructural factors might be at the root of trade-offs.

In terms of the compatibility situations depicted in our study (e.g.; significant and positive associations between two or more capabilities), these relationships are commonly found in previous studies (e.g.; Collins et al; 1998; Fynes et al; 2000; Rosenzweig and Roth, 2004; Flynn and Flynn, 2004). These and similar investigations show a number of relationships in which different capabilities observe a positive and significant regression/correlation coefficient. Oftentimes, these compatibilities are associated with higher implementation levels of practices such as TQM, TPM and related programs (e.g.; Morita and Flynn, 1997; Collins et al, 1998, Fynes et al, 2000).

With regards to the more holistic approach discussed in sections 2 and 3, only two studies (Filippini et al, 1998; Corbett and Claridge, 2002) were found to utilise a methodology similar to it. In those investigations, the authors group the subjects based on the levels of performance achieved along several capabilities and classify the firms in terms of the number of manufacturing capabilities in which they actually achieve what could be considered as a "high level of performance". Interestingly, the results in both studies show that, generally, achieving high performance along multiple capabilities is difficult, a result that arguably is consistent with Skinner's trade-off and focused factory concepts (e.g.; 1969, 1974). Furthermore, Filippini et al (1998), by means of a new methodology, establish the presence of trade-offs and compatibilities between some pairs of manufacturing capabilities, even when there is no significant correlation between them. For example, Filippini et al (1998) arrive at the conclusion that there are strong compatibilities between "delivery time" and "quality consistency", in spite of the absence of a significant and positive correlation between those capabilities. Like 
ours, their investigation also extends the definition of compatibilities and trade-offs beyond the obtention of significant positive and negative correlations.

The preceding discussions have important implications. The use of probabilistic and linear regression/correlation analyses and related methods (e.g.; path analysis) to determine the existence of trade-offs and compatibilities in a sample of subjects is a limited approach. A negative and significant regression/correlation coefficient might be a good indicator of the latent existence of a differential in performance between two variables, something that is consistent with the definition of a trade-off relationship. Nonetheless, as our investigation shows, in the case of significant and positive overall patterns, exclusive regression/correlation analyses are incapable of identifying the potential presence of a frontier trade-off. Such evidence between two capabilities might indicate a general level of compatibility. However, care should be exercised when interpreting such results, as a positive and significant regression/correlation line tends to "mask" or "hide" a frontier trade-off. Thus, a more holistic and deterministic analysis should acknowledge both the levels of compatibilities observed, and also the performance shortfalls with respect to higher levels of achievement, leaving open the possible presence of a frontier trade-off that would explain such shortfalls. Extra analyses focusing on the best performers (e.g.; a benchmark approach) are needed in order to identify the shortfalls in performance with respect to the highest levels of achievement.

It can also be concluded that, when past investigations (e.g.; Fynes et al; 2000; Flynn and Flynn, 2004) have claimed to find evidence that does not support the existence of trade-offs amongst the variables under study, in reality they have found evidence only against the zero-sum type of trade-off. The absence of a negative and significant relationship between two capabilities would seem to indicate that a gain in one would not necessarily mean a more direct, linear-type of loss in the other one. This would give basis to assert the absence of trade-offs of the zero-sum type. However, as we have shown, the absence of a zero-sum trade-off between two capabilities does not necessarily mean the absence of a frontier trade-off. Although these two trade-offs entail a differential in performance between two capabilities, they are considerably different, and require separate types of analyses in order to conclusively assert that they are not present within a sample. Consequently, future studies, while commenting on the absence of a significant and negative relationship between two criteria, could also make a distinction and conclude that evidence does 
not support the presence of trade-offs, but only of the zero-sum type, and that frontier trade-offs could still be present.

\section{Conclusions and suggestions for future research}

This investigation argues for the existence of two types of compromised relationships: Zero-sum and frontier trade-offs. These phenomena have been empirically and/or theoretically discussed and found in previous research, particularly in the operations management literature. Our proposal addresses some of the problems that past research has left unattended and that were discussed in section 3. Zero-sum trade-offs are characterised by a negative and significant relationship between different variables representing manufacturing capabilities. On the other hand, frontier trade-offs are hypothesised to be observed in a relationship in which different criteria can observe some degree of compatibility, a level after which a differential in performance will be observed. This is consistent with the performance frontier concept advanced by Schmenner and Swink (1998) and also with the research by other authors (e.g.; Skinner 1992, 1996; Porter, 1996). Furthermore, both zero-sum and frontier trade-offs indicate that, generally speaking, different capabilities affected by either trade-off will not achieve an "outstanding enough to create competitive advantage" level of performance at the same time and under the same circumstances, something that is consistent with the foundational principles of the trade-off model. To the best of our knowledge, our study is the first one that formally establishes and recognises these different types of trade-offs and that also reconciles the differences between previous approaches and rationales and more recent theoretical advancements.

Frontier trade-offs imply a change in the way that compromised relationships are established in quantitative studies. It is important not only to analyse a sample with linear regression/correlation analyses. The possible presence of frontier tradeoffs also entails a need to rank the observations (e.g.; manufacturing firms) in terms of their actual performance achieved. This will allow the analyst to observe whether an "outstanding enough to create advantage" level of performance has been achieved along multiple capabilities by one or more firms, and also to determine if this phenomenon is consistent with overall trends within the sample as represented by significant correlation coefficients. Moreover, the absence of a negative and significant correlation coefficient between two variables has been interpreted as the 
absence of a compromised relationship. While this rationale can still be used to assert the absence of a zero-sum trade-off, unless there is conclusive evidence to the contrary, the potential existence of a frontier trade-off should be recognised. For example, when analysing multiple manufacturing capabilities, and in the presence of significant and positive correlations, it should be acknowledged that while there seems to be no evidence of zero-sum trade-offs, frontier trade-offs could still be present. Put differently, since the absence of zero-sum and frontier trade-offs can only be unmistakeably established if, and only if, different capabilities observe an "outstanding enough to create competitive advantage" level of performance at the same time, relationships in which at least one capability attains a lesser level of performance should be assessed considering the compatibilities and also the shortfalls in achievement observed, leaving the potential existence of frontier tradeoffs as a possible explanatory variable for the performance shortfalls.

The heuristic approach and rationale to the analysis of trade-offs and compatibilities that we are proposing can also be extended to research that includes more than two capabilities, both at the individual firm and at the group level. For example, let us suppose that a manufacturing firm observes $5,5,3$, and 4 levels of achievement along "cost", "delivery", "quality" and "flexibility". Based on our rationale, it could be concluded that compatibilities amongst these capabilities are observed up to the "3" level of performance, a level after which varying performance achievements are observed, something that could be indicative of the existence of a frontier tradeoff amongst this group of capabilities. Frontier trade-offs can also be studied by means of longitudinal case studies with individual firms. As figure 3 and footnote 1 imply, a firm could observe a "5" and a " 4 " levels of achievement in various criteria. Researchers could then investigate whether that gap in performance widens, disappears of stays unchanged over time, and the causes behind it.

Studies with real firms can not be expected to match the ideal conditions of our analytical investigation in section 3. From this premise, it follows that the issues raised by our research can become even more difficult in real-life studies. Therefore, we believe that our comments and proposals are even more relevant and valid when real-firms are included in an investigation. For example, the analyses and discussions in section 3 are based on the assumption of similar asset frontiers in all the participants. While this is useful to illustrate the nature of frontier trade-offs and its implications, it is possible that, in real-life investigations, a sample of subjects can include firms that have different asset frontiers, even when they belong to the same 
industry and context and/or are direct competitors. In other words, different asset frontiers could result in frontier trade-offs between different pairs of criteria in different individual firms. In such situations, our recommendation is to include as many manufacturing capabilities as possible in the analysis so that the shortfalls in performance with respect to higher levels of achievement can be identified. Since trade-offs are real and exist in all manufacturing firms, differentials in performance between pairs of competitive criteria should be expected and observed, either by means of regression/correlation analyses and/or other methodologies such as the benchmark approach we advance.

Although the questions posed at the end of section 2 have been answered already, we are laying them out again: linear regression/correlation analyses and related approaches are sufficient to identify overall compatibilities, but insufficient with regards to (frontier) trade-offs that can exist at the same time in a relationship between different criteria. New approaches need to be added to the analysis, including those with a "benchmark" focus as proposed in section 3. Past rationales and assumptions can be reconciled with more recent theoretical developments by acknowledging the existence of both zero-sum and frontier trade-offs.

Recently, Schonberger (2007) wrote that “... two decades later, trade-off viewpoints seem much suppressed. As Boyer and Lewis (2002) suggest, trade-offs may be irrelevant in this hypercompetitive global economy that presses for improvement in multiple dimensions. Academic interest has shifted largely to the nature and subtleties of multiple or cumulative capabilities (e.g., Flynn and Flynn, 2004)". We are modestly proposing that finer phenomena such as frontier trade-offs might be getting overlooked amongst overall positive and significant linear regression/correlation coefficients. While improvements and compatibilities might be achieved simultaneously along different criteria, we believe that trade-offs amongst them are still existent, relevant, and thus important for a long-lasting competitive advantage. We are inviting our colleagues to think of compromised relationships not only as those consistent with a zero-sum trade-off, but also to consider that frontier trade-offs are a real possibility. We hope that future researchers will take this up as a topic for their investigations. 


\section{References}

Antonio, K. W. L., Yam, R. C. M., Tang, E. 2007. The impact of product modularity on competitive capabilities and performance: An empirical study. International Journal of Production Economics, 105 (1), 1-20.

Boyer, K. K., Lewis, M. W. 2002. Competitive priorities: investigating the need for trade-offs in operations strategy. Production and Operations Management, 11 (1), 920.

Collins, R. S., Cordon, C., Julien, D. 1998. An empirical test of the rigid flexibility model. Journal of Operations Management, 16 (2), 133-146.

Corbett, L.M., Whybark, D.C. 2001. Searching for the sand cone in the GMRG data. International Journal of Operations and Production Management, 21 (7), 965-980.

Corbett, L.M., Claridge, G.S. 2002. Key manufacturing capability elements and business performance. International Journal of Production Research, 40 (1), 109131.

da Silveira, G., Slack, N. 2001. Exploring the trade-off concept. International Journal of Operations Management, 21 (7), 949-964.

da Silveira, G. J. C. 2005. Improving trade-offs in manufacturing: Methods and illustration. International Journal of Production Economics, 95 (1), 27-38.

da Silveira, G. J. C. 2006. Effects of simplicity and discipline on operational flexibility: An empirical re-examination of the rigid flexibility model. Journal of Operations Management, 24 (6), 932-947.

Dostaler, I. 2000. Trying to resolve manufacturing performance trade-offs: The case of British electronic contract electronic assemblers. Canadian Journal of Administrative Sciences, 17 (3), 255-268.

Dostaler, I. 2001. Beyond practices: A qualitative inquiry into high performance electronics assembly. Productions and Operations Management, 10 (4), 478-493. 
Ferdows, K., de Meyer, A. 1990. Lasting improvements in manufacturing performance: In search of a new theory. Journal of Operations Management, 9 (2), 168-184.

Filippini, R., Forza, C., Vinelli, A. 1998. Trade-off and compatibility between performance: Definitions and empirical evidence. International Journal of Production Research, 36 (12), 3379-3406.

Flynn, B.B., Schroeder, R.G., Flynn, E.J. 1999. World class manufacturing: An investigation of Hayes and Wheelwright's foundation. Journal of Operations Management, 17 (3), 249-269.

Flynn, B. B., Flynn, E. J., 2004. An exploratory study of the nature of cumulative capabilities. Journal of Operations Management, 22 (5), 439-457.

Folger, R., Turillo, C. J. 1999. Theorising as the thickness of thin abstraction. Academy of Management Review, 24 (4), 742-758.

Fynes, B., de Burca, S., Brannick, T., Glynn, W.J. 2000. Quality practices, quality performance and business performance: A test of the "trade-off" and "multiple capability" theories. IBAR, 21 (1), 29-50.

Fynes, B., Voss, C., de Burca, S. 2005. The impact of supply chain relationship dynamics on manufacturing performance. International Journal of Operations and Production Management, 25 (1), 6-19.

Grobler, A., Grubner, A. 2006. An empirical model of relationships between manufacturing capabilities. International Journal of Operations and Production Management, 26 (5), 458-485.

Hayes, R.H.; Wheelwright, S.C. 1984. Restoring our competitive edge: Competing through manufacturing. John Wiley and Sons, New York.

Hill, T. 1995. Manufacturing strategy: Text and cases. Macmillan Press Ltd. London, UK. 
Lapre, M. A., Scudder, G. D. 2004. Performance improvement paths in the U. S. airline industry: Linking trade-offs to asset frontiers. Production and Operations Management, 13 (2), 123-134.

Mapes, J., New, C., Szwejczewski, M. 1997. Performance trade-offs in manufacturing plants. International Journal of Operations and Production Management, 17 (10), 1020-1033.

Mapes, J., Szwejczewski, M., New, C. 2000. Process variability and its effect on plant performance. International Journal of Operations and Production Management, 20 (7), 792-808.

Mintzberg, H., Lampel, J., Quinn, J. B., Ghoshal, S. 2003. The Strategy Process: Concepts, contexts, cases. Pearson Education Limited, Essex, UK.

Morita, M., Flynn, E.J. 1997. The linkage amongst management systems, practices and behaviour in successful manufacturing strategy. International Journal of Operations and Production Management, 17 (10), 967-993.

Narasimhan, R., Swink, M., Kim, S. W. 2005. An exploratory study of manufacturing practice and performance interrelationships. International Journal of Operations and Production Management, 25 (10), 1013-1033.

New, C. 1992. World-class manufacturing versus strategic trade-offs. International Journal of Operations and Production Management, 12 (6), 19-31.

Noble, M. A. 1995. Manufacturing strategy: Testing the cumulative model in a multiple country context. Decision Sciences, 26 (5), 693-721.

Popper, K. 2002. The logic of scientific discovery, Routledge Classics, Taylor \& Francis Group, London and New York.

Porter, M. E. 1980. Competitive Strategy: Techniques for Analyzing Industries and Competitors. The Free Press, Collier Macmillan Publishers, London.

Porter, M. E. 1985. Competitive Advantage: Creating and Sustaining Superior Performance. Free Press, London. 
Porter, M. E. 1996. What is strategy? Harvard Business Review November December, 61-78.

Rosenzweig, E. D., Roth, A. V. 2004. Towards a theory of competitive progression: Evidence from high-tech manufacturing. Production and Operations Management, 13 (4), 354-368.

Roth, A. V.; Miller, J. G. 1990. Manufacturing strategy, manufacturing strength, managerial success and economic outcomes. In: Ettlie, J, E.; Burstein, M, C.; Fiegenbaum, A. (Eds.), Manufacturing strategy: The research agenda for the next decade, proceedings of the joint industry conference on manufacturing strategy, January 8-9, Ann Arbor, Michigan, USA, 97-108.

Roth, A. V., Miller, J.G. 1992. Success factors in manufacturing. Business Horizons July-August, 73-81.

Safizadeh, M.H., Ritzman, L. P., Mallick, D. 2000. Revisiting alternative theoretical paradigms in manufacturing strategy. Production and Operations Management, 9 (2), 111-127.

Sarmiento, R., Byrne, M., Contreras, L. R., Rich, N. 2007. Delivery reliability, manufacturing capabilities and new models of manufacturing efficiency. Journal of Manufacturing Technology Management, 18 (4), 367-386.

Sarmiento, R., Sarkis, J., Byrne, M. 2009. Manufacturing capabilities and performance: a critical analysis and review. International Journal of Production Research (forthcoming).

Schmenner, R.W., Swink, M. L. 1998. On theory in operations management. Journal of Operations Management, 17 (1), 97-113.

Schonberger, R. J. 1986. World class manufacturing: The lessons of simplicity applied. The Free Press, New York.

Schonberger, R. J. 1990. Building a chain of customers. Hutchinson Business Books, London. 
Schonberger, R. J. 2007. Japanese production management: an evolution - with mixed success. Journal of Operations Management, 25 (2), 403-419.

Schroeder, R.G.; Flynn, E.J.; Flynn, B.B.; Hollingworth, D. 1996. Manufacturing performance trade-offs: An empirical investigation. $3^{\text {rd }}$ International Conference of the European Operations Management Association, June 2-4London, UK.

Skinner, W. 1969. Manufacturing-Missing Link in Corporate Strategy. Harvard Business Review May-June, 136-145.

Skinner, W. 1974. The Focused Factory. Harvard Business Review May-June, 113121.

Skinner, W. 1992. Missing the links in manufacturing strategy. In Voss, C.A. (Ed), Manufacturing Strategy: Process and Content, Chapman and Hall, London, 13-25.

Skinner, W. 1996. Manufacturing strategy on the "S" curve. Production and Operations Management, 5 (1), 3-14.

Squire, B., Brown, S., Readman, J., Bessant, J. 2006. The impact of mass customisation on manufacturing trade-offs. Production and Operations Management, 15 (1), 10-21.

Stratton, R., Warburton, D. H. 2003. The strategic integration of agile and lean supply chain. International Journal of Production Economics, 85 (2), 183-198.

Stratton, R., Warburton, D. H. 2005. Managing the trade-offs implications of global supply. International Journal of Production Economics, 103 (2), 667-669.

Swink, M., Talluri, S., Pandejpong, T. 2006. Faster, better, cheaper: a study of NPD project efficiency and performance tradeoffs. Journal of Operations Management, 24 (5), 542-562.

Szwejczewski, M., Mapes, J., New, C. 1997. Delivery and trade-offs. International Journal of Production Economics, 53 (3), 323-330. 
Vastag, G. 2000. The theory of performance frontiers. Journal of Operations Management, 18 (3), 353-360. 


\section{Figure 1}

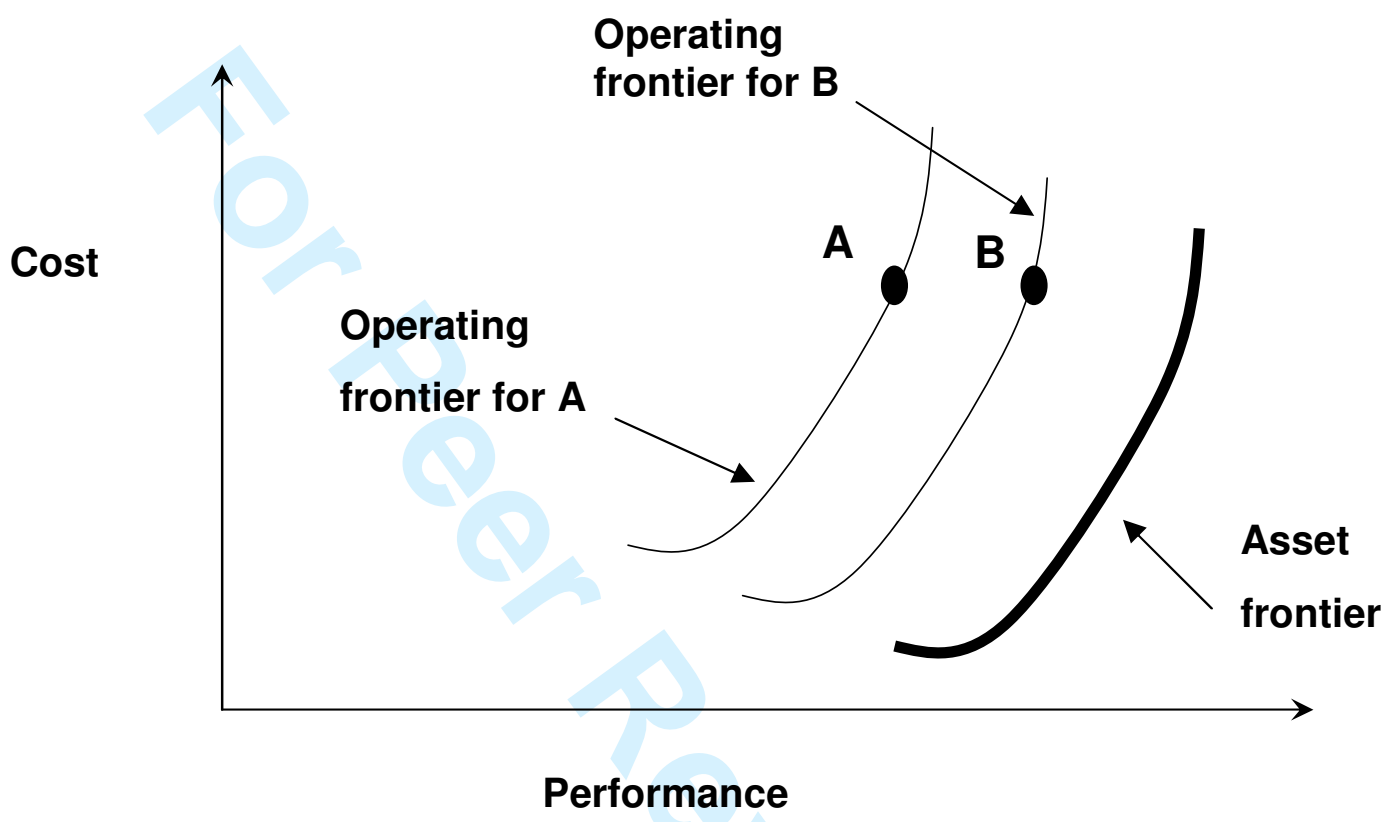

Figure 1. Operating and asset frontiers. Firm $A$ is likely to operate under the laws of cumulative capabilities while firm $B$, due to diminishing returns on improvement is more likely to be subject to the law of trade-offs. (adapted from Schmenner and Swink, 1998). 


\section{Figure 2}

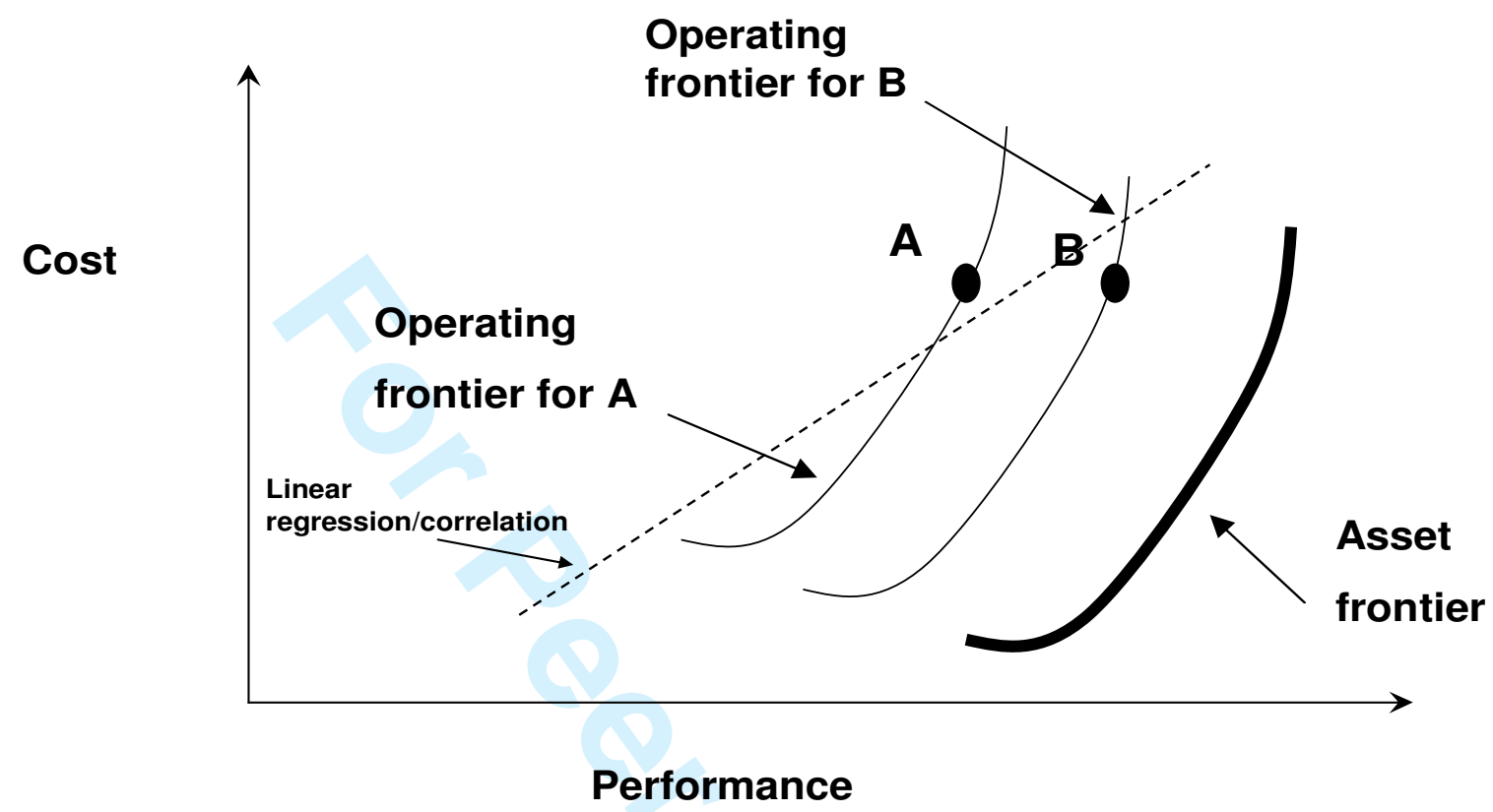

Figure 2. Original theory of performance frontiers illustration with the addition of a regression/correlation line that represents the "cumulative capabilities" implied by the framework. 


\section{Figure 3}

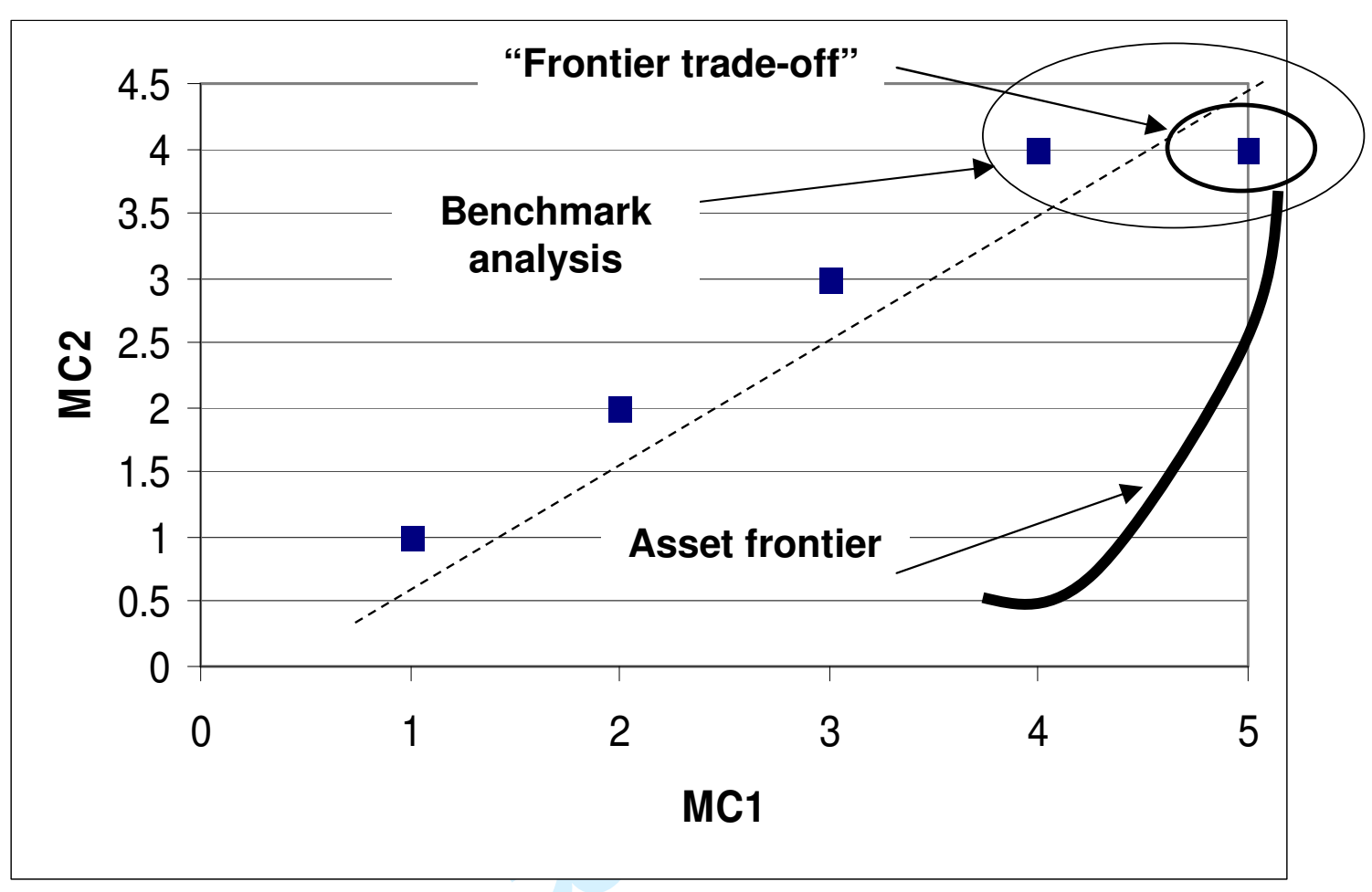

Figure 3. Frontier trade-off and cumulative capabilities between MC1 and MC2

= Manufacturing Firms A, B, C, D, E, from left to right. = Linear regression/correlation analysis 


\section{Figure 4}

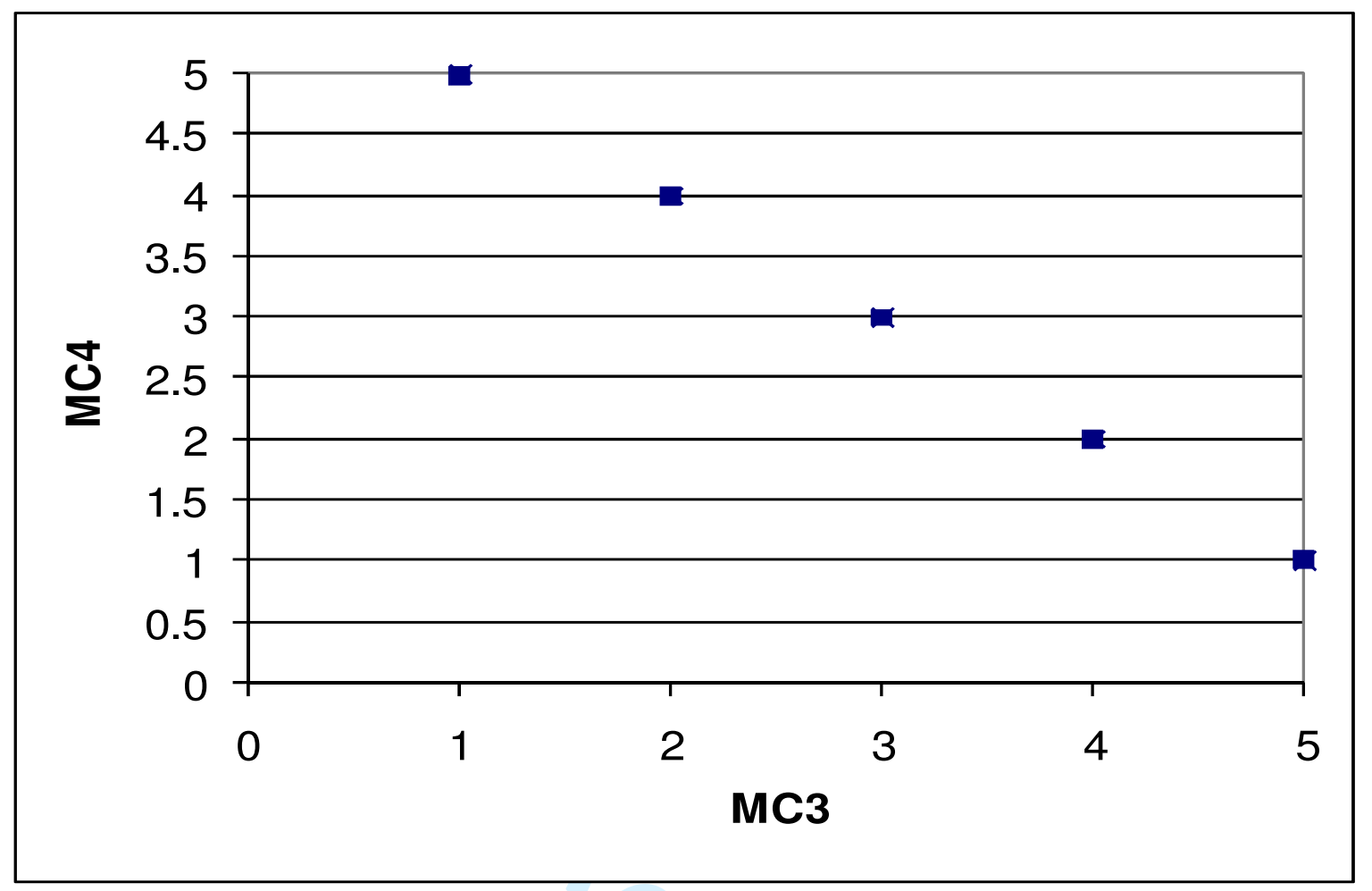

Figure 4. Zero-sum trade-off between MC3 and MC4.

= Manufacturing Firms A, B, C, D, E, from left to right. 